University of Wollongong

Research Online

Australian Institute for Innovative Materials -

Papers

Australian Institute for Innovative Materials

$1-1-2017$

\title{
Silica Nanoparticles Functionalized with Zwitterionic Sulfobetaine Siloxane for Application as a Versatile Antifouling Coating System
}

Brianna Knowles

University of Wollongong, bs921@uowmail.edu.au

Pawel W. Wagner

University of Wollongong, pawel@uow.edu.au

Shane A. MacLaughlin

University of Wollongong

Michael J. Higgins

University of Wollongong, mhiggins@uow.edu.au

Paul J. Molino

University of Wollongong, pmolino@uow.edu.au

Follow this and additional works at: https://ro.uow.edu.au/aiimpapers

Part of the Engineering Commons, and the Physical Sciences and Mathematics Commons

Research Online is the open access institutional repository for the University of Wollongong. For further information contact the UOW Library: research-pubs@uow.edu.au 


\title{
Silica Nanoparticles Functionalized with Zwitterionic Sulfobetaine Siloxane for Application as a Versatile Antifouling Coating System
}

\author{
Abstract \\ The growing need to develop surfaces able to effectively resist biological fouling has resulted in the \\ widespread investigation of nanomaterials with potential antifouling properties. However, the preparation \\ of effective antifouling coatings is limited by the availability of reactive surface functional groups and our \\ ability to carefully control and organize chemistries at a materials' interface. Here, we present two \\ methods of preparing hydrophilic low-fouling surface coatings through reaction of silica-nanoparticle \\ suspensions and predeposited silicananoparticle films with zwitterionic sulfobetaine (SB). Silica- \\ nanoparticle suspensions were functionalized with SB across three $\mathrm{pH}$ conditions and deposited as thin \\ films via a simple spin-coating process to generate hydrophilic antifouling coatings. In addition, coatings \\ of predeposited silica nanoparticles were surface functionalized via exposure to zwitterionic solutions. \\ Quartz crystal microgravimetry with dissipation monitoring was employed as a high throughput technique \\ for monitoring and optimizing reaction to the silica-nanoparticle surfaces. Functionalization of \\ nanoparticle films was rapid and could be achieved over a wide $\mathrm{pH}$ range and at low zwitterion \\ concentrations. All functionalized particle surfaces presented a high degree of wettability and resulted in \\ large reductions in adsorption of bovine serum albumin protein. Particle coatings also showed a \\ reduction in adhesion of fungal spores (Epicoccum nigrum) and bacteria (Escherichia coli) by up to 87 \\ and $96 \%$, respectively. These results indicate the potential for functionalized nanosilicas to be further \\ developed as versatile fouling-resistant coatings for widespread coating applications.

\section{Disciplines} \\ Engineering | Physical Sciences and Mathematics

\section{Publication Details} \\ Knowles, B. R., Wagner, P., MacLaughlin, S., Higgins, M. J. \& Molino, P. J. (2017). Silica Nanoparticles \\ Functionalized with Zwitterionic Sulfobetaine Siloxane for Application as a Versatile Antifouling Coating \\ System. ACS Applied Materials and Interfaces, 9 (22), 18584-18594.
}


Supporting Information

\section{Silica Nanoparticles Functionalized with Zwitterionic}

\section{Sulfobetaine Siloxane for Application as a Versatile}

\section{Antifouling Coating System}

Brianna R. Knowles ${ }^{a, b, c}$, Pawel Wagner $^{a}$, Shane Maclaughlin ${ }^{b, c}$, Michael J. Higgins $^{a, b}$, Paul J.

$\operatorname{Molino}^{a, b *}$

antelligent Polymer Research Institute, ARC Centre of Excellence for Electromaterials Science

AIIM Facility, Innovation Campus, University of Wollongong, Wollongong, NSW 2522, Australia

${ }^{\mathrm{b}}$ ARC Research Hub for Australian Steel Manufacturing

${ }^{\mathrm{c}}$ BlueScope Innovation Laboratories, Old Port Road, Port Kembla, NSW 2505, Australia

\section{Corresponding Author}

*Email: pmolino@uow.edu.au 


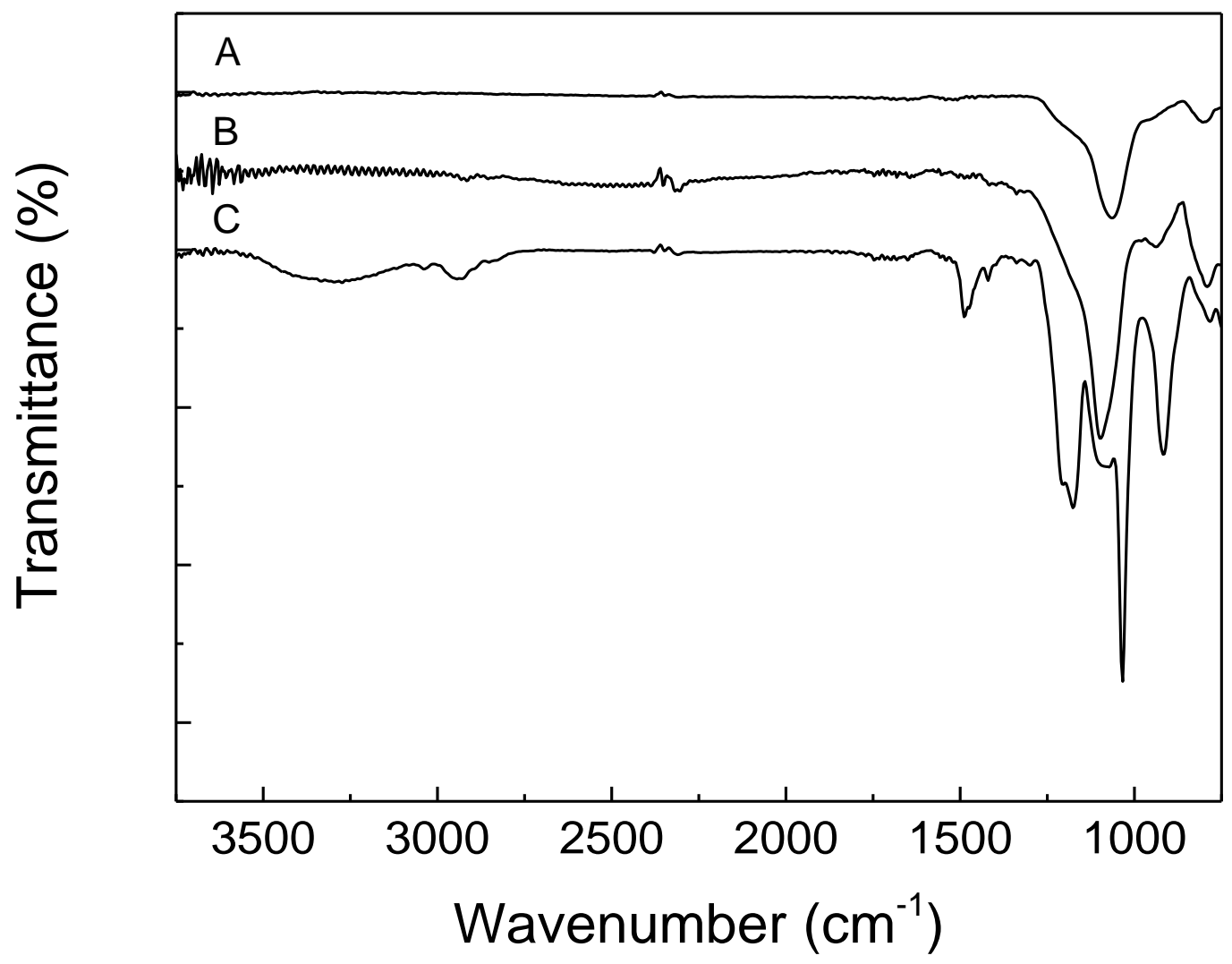

Figure S1. FTIR of (A) unfunctionalised SiNP, (B) SiNP + SB and (C) SB.

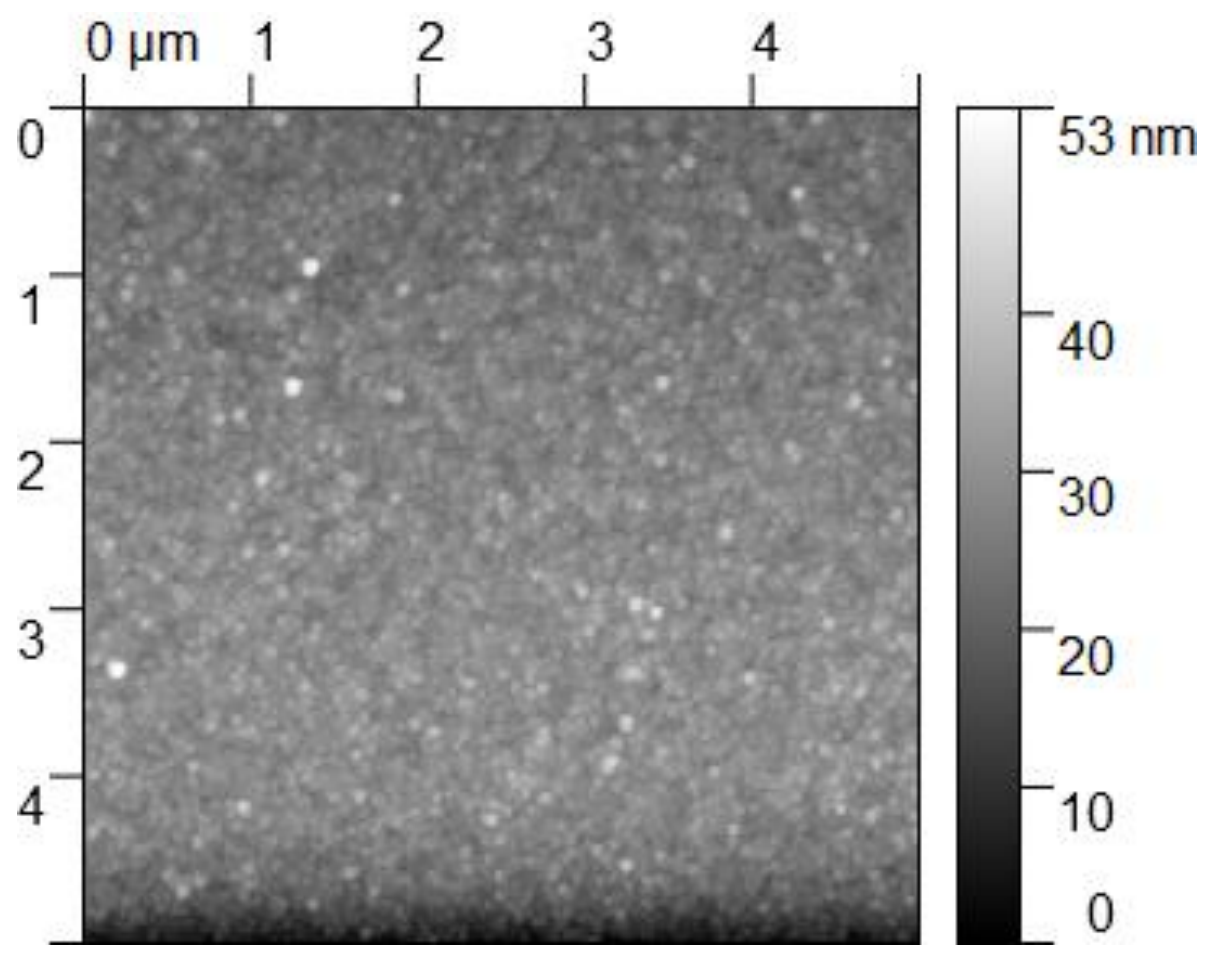

Figure S2. AFM scan $(5 \mu \mathrm{m} x 5 \mu \mathrm{m})$ of a Ludox $+\mathrm{SB}$ (pH9.5) particle coating. 


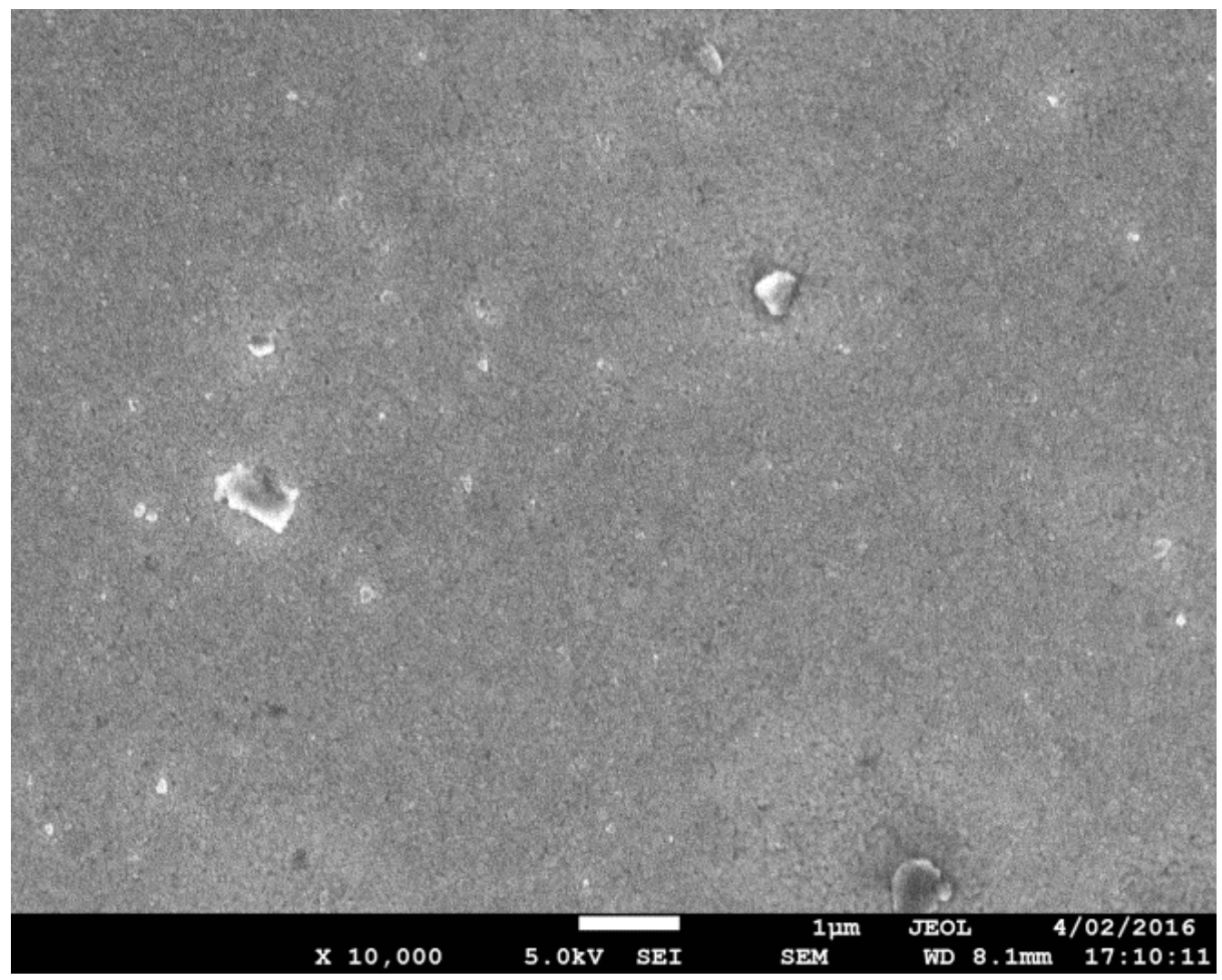

Figure S3. SEM image of Ludox + SB (pH3.5) coating showing the presence of aggregates

Table S1. Water contact angles of coatings prepared from 4wt $\%$ silica nanoparticle solutions.

\begin{tabular}{lcccc}
\hline & \multicolumn{5}{c}{ Contact Angle $\left(^{\circ}\right)$} \\
\cline { 2 - 5 } Coating & Control & $\mathbf{p H 3 . 5}$ & $\mathbf{p H 7 . 0}$ & $\mathbf{p H 9 . 5}$ \\
\hline SiNP Control & $9.5 \pm 0.3$ & - & - & - \\
SiNP - 1mM SB & - & $6.1 \pm 0.4$ & $5.6 \pm 0.5$ & $5.4 \pm 0.4$ \\
SiNP - 10mM SB & - & $5.9 \pm 0.5$ & $5.6 \pm 0.7$ & $5.9 \pm 0.4$ \\
SiNP + SB & - & $3.6 \pm 0.3$ & $4.8 \pm 0.7$ & $5.3 \pm 0.2$ \\
\hline
\end{tabular}


Table S2. Hydrodynamic diameter and polydispersity index (PDI) of SiNPs after functionalisation with $\mathrm{SB}$ at various $\mathrm{pH}$ conditions.

\begin{tabular}{lcc}
\hline & Z-Ave (d.nm) & PDI \\
\hline SiNP Control & 18.29 & 0.20 \\
SiNP + SB (pH3.5) & 147.93 & 0.51 \\
SiNP + SB (pH7.0) & 24.93 & 0.46 \\
SiNP + SB (pH9.5) & 30.10 & 0.49 \\
\hline
\end{tabular}

Table S3. Degree of surface functionalisation as determined by TGA analysis.

\begin{tabular}{lccc}
\hline SiNP + SB & \% Mass loss & umol $/ \mathbf{m}^{2}$ & silanol $/ \mathbf{n m}^{2}$ \\
\hline $\mathrm{pH} 3.5$ & 4.54 & 0.78 & 0.47 \\
$\mathrm{pH} 7.0$ & 6.92 & 1.22 & 0.73 \\
$\mathrm{pH} 9.5$ & 6.11 & 1.06 & 0.64 \\
\hline
\end{tabular}

